\title{
Lichen amyloidosus
}

\begin{tabular}{|l|l|}
\hline A. & Pype \\
\hline In 1950 this 61 -year-old woman had started developing on her abdomen, back and limbs
\end{tabular} strongly pruriginous lesions consisting of hyper- and hypopigmentated plaques, with excoriations, crusts and lichenification; dome-shaped, yellow-brown to grey and slightly hyperker-atotic papules were also found among the lesions (fig. 7). Histologically, amorphous Congo-red-positive material was located in the papillae. The laboratory tests disclosed a sedimentation rate of 30/58, an increased total protein content (8.5 g\%) with a high IgG level (2,319 mg\%; normal 560-1,512 mg\%).

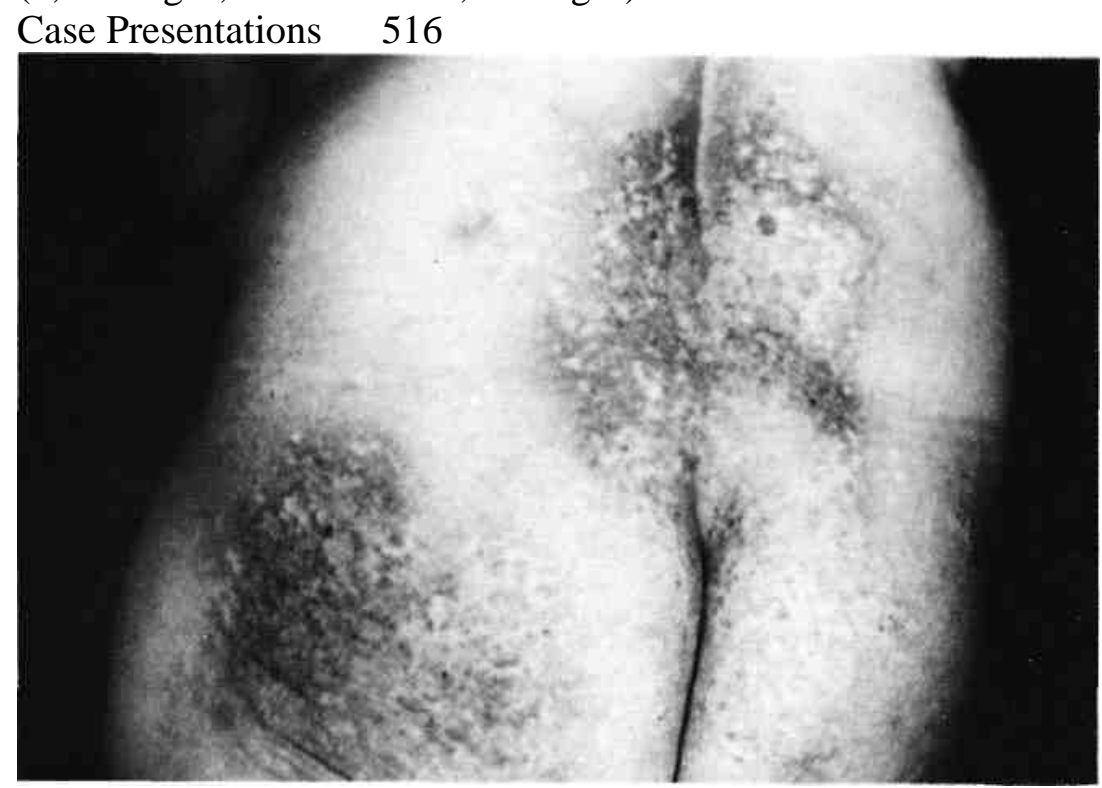

Fig. 7. Lichen amyloidosus: hyper- and hypopigmented, slightly lichenified plaques, with numerous hyperkeratotic papules.

Livedo Vasculitis

M.L. Geerts, Ph. Hindryckx

S ..., Eddy, an 18-year-old male has suffered from slightly pruriginous skin lesions for 1.5 years. The lesions started on the inner ankles and extended progressively to the legs and the dorsa of the feet.

The lesions on the ankles and lower legs consisted of many light-brown macules, telan-giectatic blood vessels, purpura and small scars resembling 'atrophie blanche' and forming a livedo-like picture (fig. 8). On the dorsa of the feet, the hands and on the posterior aspect of the forearms there were numerous dilated capillaries arranged in clews. Histologically (fig. 9), the blood vessels of the upper and middle portion of the dermis were thickened and partly destroyed by hyaline degeneration and focal thrombosis. The capillaries were surrounded by lymphocytes, histiocytes and a few polymorphonuclear cells. The connective tissue of the dermis was partially 
homogenized. On direct immunofluorescence, IgM, IgG, IgA and C3 were located in the diseased vessel walls. The laboratory and clinical tests were normal. The patient was treated with elastic bandages.

The skin lesions on the ankles and the lower legs and their histological picture were identical with the ones described by Bard and Winkelmann [1967] as livedo vasculitis, or 